\title{
Optical coherence tomography angiography findings in macular telangiectasia type 2 in Mexican patients
}

\section{Hallazgos en la angiografía por tomografía de coherencia óptica en pacientes mexicanos con telangiectasias maculares tipo 2}

\author{
Paola Brito-Sandoval* and Sergio Rojas-Juárez \\ Retina and vitreous department, Fundación Hospital Nuestra Señora de la Luz, IAP, Mexico City, Mexico
}

\begin{abstract}
Purpose: To describe the characteristics of perifoveal capillaries, the plexuses involved and changes of the neurosensory retina in idiopathic macular telangiectasia using optical coherence tomography angiography (OCT-A) and correlate these findings with visual acuity. Method: Descriptive and analytical study. Heidelberg OCT-A was performed in patients diagnosed with Type 2 macular telangiectasia. Results: $A$ total of 43 eyes of 24 adult patients were studied. Average age was of 60 years, and $80 \%$ of the cases were bilateral. Diabetic patients had significantly worse visual acuity $(p<0.05)$. Regarding vascular changes, we found $21 \%$ in Stage 1,38\% in Stage 2, 32\% in Stage 3 and 9\% in Stage 4. The most frequent location of vascular changes by OCT-A with respect to the fovea was temporal (63\%), followed by superior (19\%). There was no relationship between the affected quadrant and visual acuity $(p=0.25)$. The deep capillary plexus was affected in $94 \%$. We found discrete thickening, dilated vessels and aneurysmal lesions. Twenty-one percent had neovascularization, $55 \%$ of these were subclinical and only detected by OCT-A. No relationship was observed between macular thickness and visual acuity $(p=0.29)$. Conclusions: We found patients in different stages of the disease; $21 \%$ had advanced disease with neovascularization and $55 \%$ had subclinical neovascularization, not detectable by fluorescein angiography and regular OCT. OCT-A is the ideal study to diagnose this disorder without the need for further studies.
\end{abstract}

Key words: Idiopathic. Macular. Telangiectasia. Optical coherence tomography.

\section{Resumen}

Objetivo: Describir por medio de la angiografía por tomografía de coherencia óptica (OCT-A) las características de los capilares perifoveales, plexos afectados y cambios de la retina neurosensorial en telangiectasias maculares idiopáticas y ver su relación con la agudeza visual. Método: Estudio descriptivo y analítico, donde se realizaron OCT-A Heidelberg en pacientes diagnosticados con telangiectasias maculares tipo 2. Resultados: Se estudiaron 43 ojos de 24 pacientes adultos. Edad promedio 60 años. El 80\% bilateral. Pacientes diabéticos con agudeza visual significativamente peor ( $p<0.05)$. Según los cambios vasculares, se encontró en estadio 1 el 21\%, en el 2 el 38\%, en 3 el 32\% y en el 4 el 9\%. La localización más frecuente de los cambios vasculares en la OCT-A con respecto a la fóvea fueron temporales (63\%), seguidos por superiores (19\%). No hay relación entre cuadrante y agudeza visual $(p=0.25)$. La afección más frecuente fue el plexo profundo (94\%).

Correspondence:

*Paola Brito-Sandoval

Ezequiel Montes, 135

Col. Tabacalera, Del. Alcaldía Cuauhtémoc Date of reception: 19-06-2019

C.P. 06030, Mexico City, Mexico

E-mail: polabs_1@ @otmail.com
Date of reception: $19-06-2019$

DOI: 10.24875/RMOE.M20000101 (http://creativecommons.org/licenses/by-nc-nd/4.0/).

Available online: 01-03-2020 Rev Mex Oftalmol (Eng). 2020;94(2):65-70 www.rmo.com.mx 
La morfología de los vasos en el sitio de la lesión fue un engrosamiento discreto, dilataciones, y en el $33 \%$ de los casos se observaron lesiones aneurismáticas, neovascularizaciones, en el 21\% (el 55\% de ellas fueron subclínicas y únicamente detectadas con OCT-A). No se encontró relación entre el grosor macular y la agudeza visual ( $p=0.29)$. Conclusiones: Encontramos pacientes en los diferentes estadios de la enfermedad. El 21\% presentó enfermedad avanzada con neovascularización y el 55\% presentó neovascularización subclínica, no detectable en fluorangiografía y OCT regular. El OCT-A es el estudio ideal para diagnosticar esta entidad sin necesidad de otros estudios.

Palabras clave: Idiopática. Mácula. Telangiectasias. Tomografía de coherencia óptica.

\section{Introduction}

Macular telangiectasia (MacTel) is characterized by abnormalities in the capillaries of the posterior pole. There are two well-defined forms: type 1, congenital or developmental, usually unilateral, with aneurysmal telangiectasis that can be part of Coats disease; and type 2, acquired in adults, usually bilateral and also called juxtafoveolar telangiectasis ${ }^{1}$.

MacTel type 2 is a degenerative condition with alteration of the macular capillaries and atrophy of the neurosensory retina, of idiopathic etiology. Its prevalence has been reported between 0.06 and $0.1 \%$, and the average age of presentation is 63 years ${ }^{1,2}$.

Vascular lesions begin temporal to the macula and subsequently affect the fovea. The superficial and deep plexuses are affected.

Histopathological features include loss of the peripheral Müller cells, with proliferation of the basal membrane towards the lumen of the retinal capillaries, reduction of the number of pericytes and focal areas of endothelial cell disruption ${ }^{3}$.

Recent evidence shows a central role of Müller cells. The changes observed by autofluorescence and optical coherence tomography (OCT) precede vascular changes in retinal fluorescein angiography (RFA) ${ }^{4}$.

RFA shows dilated capillaries and capillary ectasia. The areas of hyper fluorescence due to contrast leakage do not correlate with macular edema. Mansour, et al. described that the foveal avascular zone is significantly increased in patients with MacTel type 2, and that subretinal neovascularization develops near areas with pigment migration ${ }^{5}$.

By OCT there is asymmetry in foveal depression and disruption of the photoreceptor inner segment/outer segment junction. This photoreceptor loss precedes the appearance of capillary changes observed by angiography. When the disease progresses, hypo reflective cavitations are observed in the inner retina that are described as macular pseudo-lamellar holes. These progress towards the outer retina and cause macular thinning and atrophy ${ }^{6}$.
OCT angiography (OCT-A) provides a three-dimensional evaluation of the neurosensory retina and retinal vasculature, and allows to perform a non-invasive mapping of the vascular plexus? ${ }^{7}$. Therefore, a combined study such as OCT-A would be ideal for studying type 2 macular telangiectasia.

According to Gass $^{8}$ there are five stages of the disease, and their characteristics are described by OCT-A. Stage 1 shows deep telangiectatic vessels located temporal to the foveal avascular zone (FAZ). In stage 2 the superficial and deep plexuses are affected, with loss of vascular density and irregular capillaries. In stage 3 the FAZ is irregular, with vascular invasion of the retinal pigment epithelium (RPE). Stage 4 shows vascular distortion and subretinal vascularization. In stage 5 there is a severe loss of vascular density and the formation of a fibrovascular disciform membrane ${ }^{9}$.

In this study, we report the morphological characteristics of the peripheral capillaries, the affected vascular plexuses and the changes in the neurosensory retina observed by OCT-A in patients with MacTel type 2 .

Additionally, we analyze if any of the variables observed by OCT-A correlate with visual acuity.

\section{Methods}

This is a descriptive, analytical and cross-sectional study where OCT-A was performed in adult patients (>18 years) diagnosed with type 2 macular telangiectasia by RFA, OCT or both. The findings observed in the images were described and analyzed to determine if these findings correlated with visual acuity. Likewise, it was determined whether demographic data influenced visual acuity or the stage of the disease.

We used the OCT Spectralis OCT-A module (Heidelberg Engineering, Germany) to acquire OCT-A images.

All patients had the study performed in both eyes, with a $3 \times 3 \mathrm{~mm}$ scan with a horizontal cut at the level of the fovea. The images were analyzed by both authors.

We included only patients with mild or moderate non-proliferative diabetic retinopathy and without macular involvement secondary to this pathology. 
Patients with retinal or macular vascular pathology due to other causes were excluded.

\section{Results}

OCT-A images were obtained from 48 eyes of 24 patients with a previous diagnosis of MacTel type 2. Only 43 eyes had changes consistent with the disorder both clinically and by RFA, OCT and OCT-A. Seventy percent were female. The average age was 60 years (46 to 77 years). We analyzed whether age correlated with a more advanced stage of the disease, but we did not observe a significant correlation ( $p=0.13$ ).

Regarding systemic diseases, $45 \%$ suffered from systemic arterial hypertension (SAH) and $29 \%$ from type 2 diabetes mellitus (T2DM); the rest denied any systemic disease. Of the diabetic patients, only three had mild non-proliferative diabetic retinopathy without diabetic macular edema; the remainder had no data of diabetic retinopathy.

After analyzing these comorbidities, we observed that diabetic patients had a significantly worse visual acuity $(p<0.05)$ than patients with arterial hypertension or without systemic diseases.

Clinically, peripheral hypopigmentation changes were observed in $100 \%$ of the eyes; in $35 \%$ of the eyes, a peri foveolar greyish coloration was observed, and 10\% showed a thickening of the macular area secondary to subretinal fluid.

The average visual acuity measured in LogMAR was of 0.3 , which is equivalent to $20 / 40$ in the Snellen chart (Table 1).

\section{Angiography findings by optical coherence tomography}

Eighty percent of the patients showed bilateral changes by OCT-A, and $20 \%$ showed unilateral changes.

Nine eyes $(21 \%)$ showed choroidal neovascularization. Four patients had evident neovascular membrane, and they received intravitreal antiangiogenic therapy. The remaining five eyes $(55 \%)$ showed subclinical neovascularization (there were no clinical, OCT or RFA signs of neovascularization), only detected in the avascular layer by OCT-A (artifacts were discarded in these patients). Patients with subclinical neovascularization had no major visual impairment (LogMAR 0.3) (Figs. 1 and 2).

The location of vascular changes by OCT-A related to the fovea was also considered, showing $63 \%$ (27) in the temporal quadrant, $19 \%$ (8), in the upper quadrant,
Table 1. Best corrected visual acuity (BCVA)

\begin{tabular}{|l|c|c|}
\hline BCVA & Number & $\%$ \\
\hline $20 / 20-20 / 40$ & 25 & 58 \\
\hline $20 / 50-20 / 80$ & 14 & 32 \\
\hline $20 / 100$ & 4 & 10 \\
\hline
\end{tabular}

$12 \%(5)$, in the nasal quadrant, and 6\% (3) in the lower quadrant. We also analyzed if visual acuity and stage correlated to the affected quadrant, but no statistically significant correlation was observed $(p=0.25$ and $p=$ 0.31 , respectively).

The most affected vascular plexus was the deep one, in $94 \%$. In $35 \%$ of patients it was possible to visualize right-angled vessels (Fig. 3). The morphological characteristics observed in the affected vessels were thickening with focal dilations and, only in $33 \%$, aneurysmal lesions (Fig. 3).

According to OCT-A staging, we found $21 \%$ in stage $1,38 \%$ in stage $2,32 \%$ in stage 3 and $9 \%$ in stage 4 . There were no patients in stage 5 .

The most common findings in the neurosensory retina by macular OCT imaging were hyperreflective spots in $86 \%$, Bruch/RPE complex discontinuity and ellipsoid line in $81 \%$, cavitation in $54 \%$ and choroidal neovascularization in $9 \%$, with macular thickening due to intraretinal fluid (Fig. 4). The average central macular thickness (CMT) was of $236 \mu \mathrm{m}$, and no significant correlation was observed between CMT and visual acuity $(p=0.29)$.

\section{Discussion}

In the MacTel Project, the largest study conducted on type 2 telangiectasia, it was observed that the most frequently associated systemic factors are diabetes $(28 \%)$ and arterial hypertension $(52 \%)^{10}$. In our study, we observed that patients with T2DM had a significantly worse visual acuity than patients with $\mathrm{SAH}$ or without systemic comorbidities. We consider this is secondary to vascular damage observed in patients with T2DM.

Age was not identified as a risk factor for a more advanced disease, since there was no significant correlation.

The pathological findings were mostly bilateral $(80 \%)$. In general, an asymmetric presentation was observed. Twenty percent of patients showed changes consistent with MacTel type 2 only in one eye (clinically, by OCT, RFA and OCT-A), and we believe this is due to the 


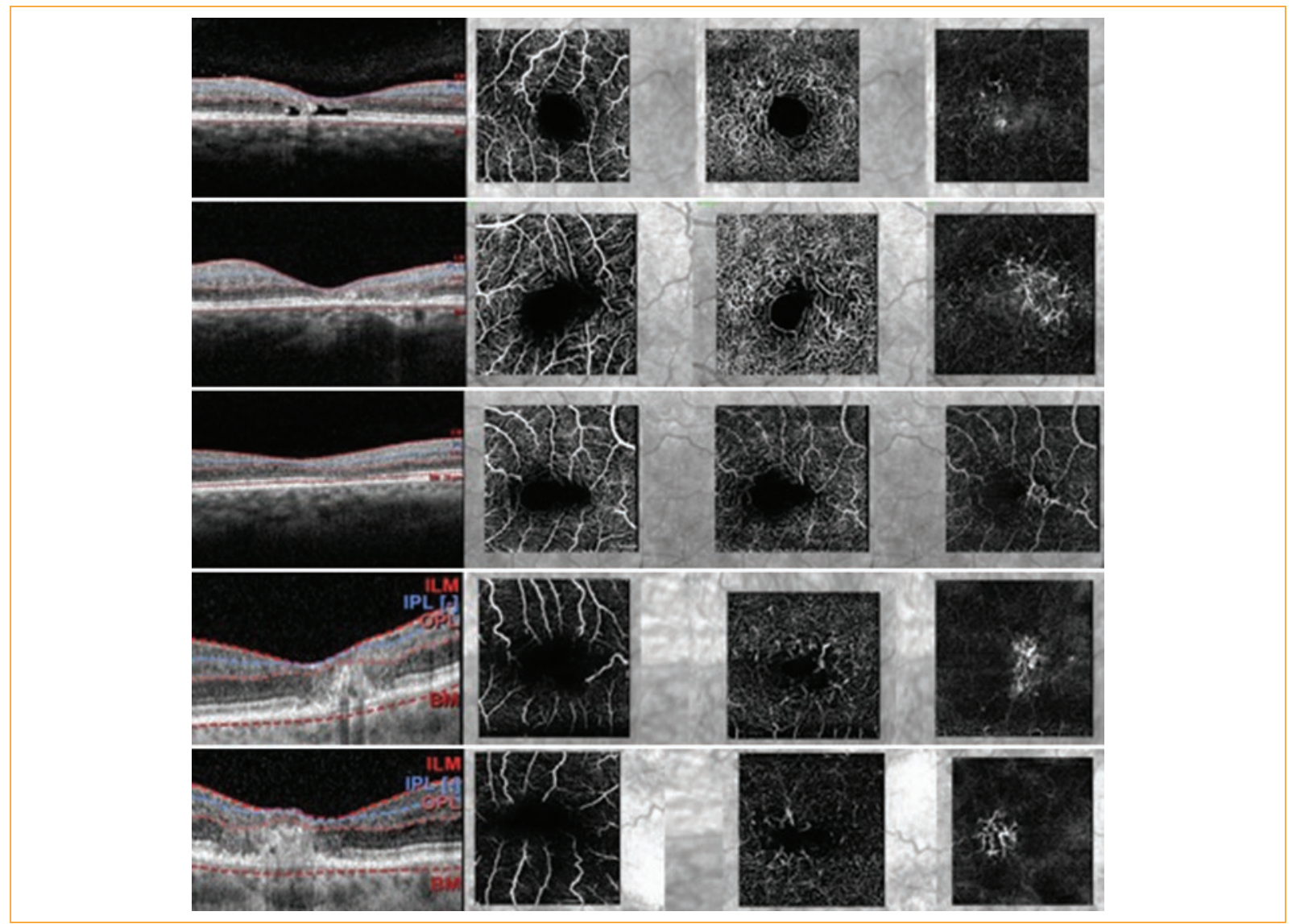

Figure 1. Optical coherence tomography angiography images of five patients with neovascularization in the avascular plexus. The first column shows images of the central macular section, the second of the superficial vascular plexus, the third of the deep plexus and the fourth of the avascular layer.

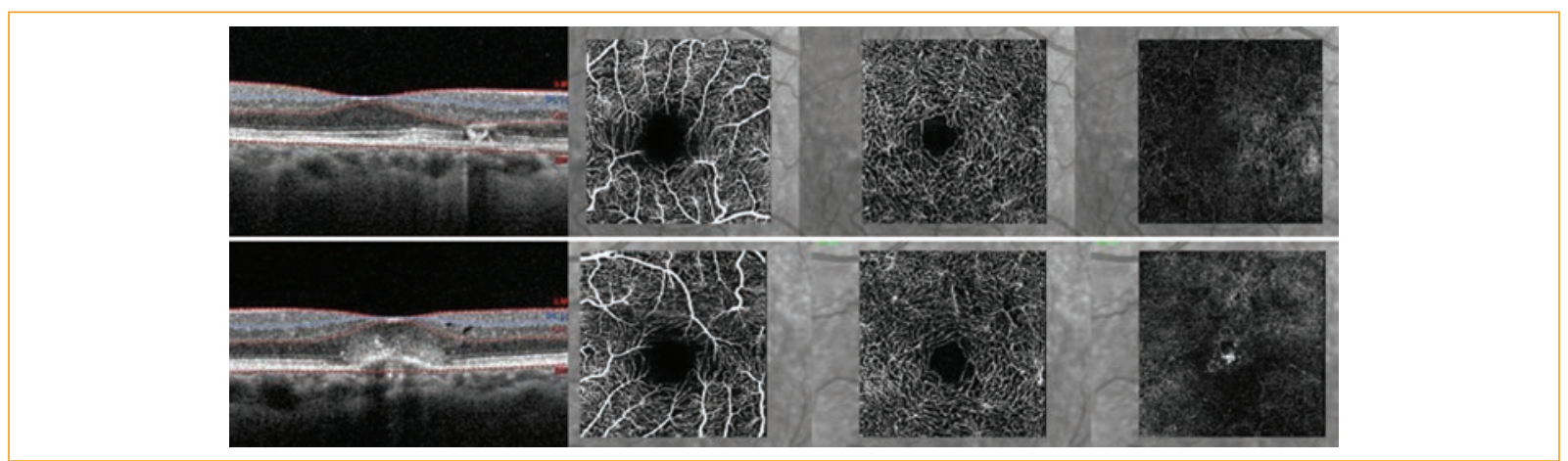

Figure 2. Top: optical coherence tomography angiography (OCT-A) of the right eye, superficial plexus with a slight decrease of vascular density, the deep plexus shows perifoveal telangiectatic vessels. Bottom: OCT-A of the left eye, showing telangiectatic vessels in the superficial and deep plexuses, loss of vascular density and neovascularization of the avascular layer.

asymmetry of the disease and not to a unilateral variety of MacTel type 2.

Overall, visual acuity was good (20/40). This is surprising in MacTel type 2, since, in other pathologies where the ellipsoid line is damaged, visual acuity is usually worse.

The MacTel Project reported a prevalence of neovascularization of $2 \%$ by examination of fundus photographs. 


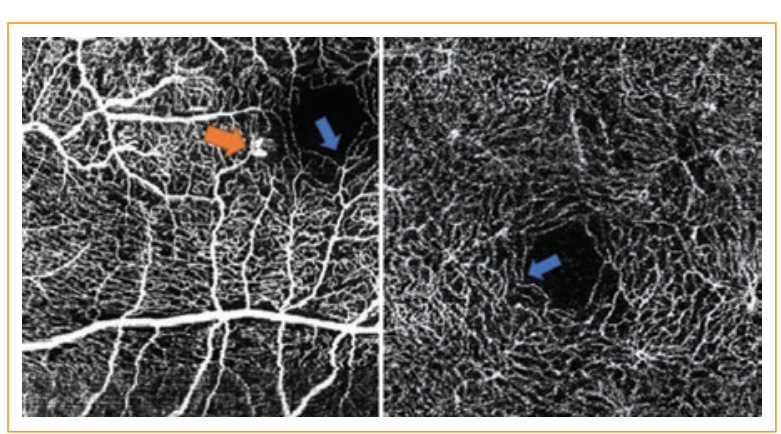

Figure 3. On the left, optical coherence tomography angiography with a vascular lesion temporal to the fovea. Aneurysmal lesion in the superficial plexus (orange arrow). Both images with right-angled vessels (blue arrow).

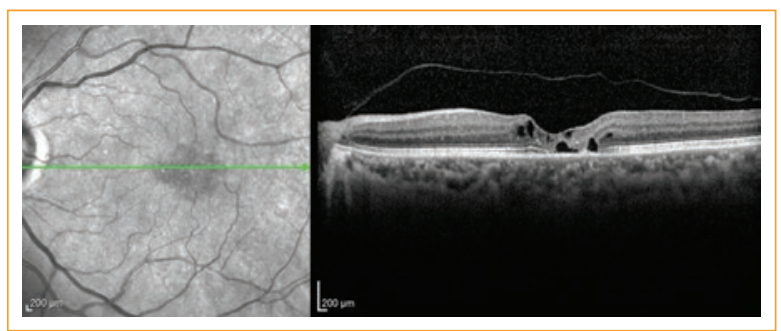

Figure 4. Characteristics of the neurosensory retina. Hyperreflective spots, intraretinal cavitations, loss of continuity of the ellipsoid line and RPE alterations.

A more recent study found vascular invasion of the outer retina and neovascularization by OCT-A in 9 of the 14 eyes studied ${ }^{11}$. In our study, by OCT-A, neovascularization was observed in $21 \%$. Fifty-five percent of these patients showed subclinical neovascularization (only by OCT-A) and did not receive antiangiogenic treatment, but they are being closely monitored.

Vascular changes mostly occurred in the temporal and upper quadrants with respect to the fovea. We found no correlation between the affected quadrant and visual acuity.

We observed a presentation of the disease in different stages. The most frequent stage was 2 , followed by stage 3 (38 and $32 \%$, respectively).

It should be noted that it is not a merely vascular disease. It has already been described that vascular changes are sometimes not the prominent feature, especially in the early stages of the disease. Gass described changes by OCT, such as lamellar holes, and by electroretinogram, a reduced response of the cones before vascular changes appearance, which reinforces the theory that the primary abnormality resides in the neural retina and in Müller cells ${ }^{12}$. The most frequent anomaly in the neurosensory retina in our case series was the loss of continuity of the ellipsoid line and alterations of external hyperreflective layers, hyperreflective spots and cavitations. Hyperreflective spots suggest a migration of cells that try to repair the damage and a probable degenerative component rather than a vascular one, since in other pathologies, such as retinitis pigmentosa, these spots have been described as extravasated lipoproteins, macrophages and RPE cells that migrate. Vascular changes may be secondary to neurosensory retina damage ${ }^{13}$. We support this theory with the studies of our patients, where changes in the neurosensory retina were more evident than vascular changes by OCT-A.

Heeren, et al. noted that visual acuity is not necessarily the best measure of functional impairment. They measured visual acuity and microperimetry. From 71 patients, $58 \%$ of the eyes showed by microperimetry an increased scotoma or a new absolute scotoma. On the other hand, only $17 \%$ of these patients had a decreased visual acuity of more than two lines ${ }^{14}$.

Finger, et al. reported that parafoveal sensory loss was associated with difficulty reading despite a stable central fixation ${ }^{15}$.

Runkle, et al. performed OCT-A in 14 eyes and observed a $50 \%$ vascular density decrease compared to controls, but concluded that the decrease in vascular density did not correlate with visual acuity. They also measured the thickness of the ellipsoid zone and the RPE, and observed that it was significantly smaller compared to the controls, and that this damage was related to a lower visual acuity ${ }^{16}$.

MacTel type 2 is an underdiagnosed disease, especially in early stages, because the changes are not very evident by examination and do not cause a significant visual loss. In late stages, its diagnosis is also difficult due to its similarity with age-related macular degeneration.

Charbel, et al. described that central macular thickness was diminished at the expense of contraction and atrophy of the outer layers of the retina; and that this was associated with disease progression ${ }^{17}$. We observed no significant correlation between CMT and visual acuity.

In our study we demonstrate the usefulness of OCT and its modality OCT-A, since it can help to identify discrete and early changes in the evolution of the disease, especially early neovascularization, which should be closely monitored. We do not believe that studies that use contrast such as fluorescein angiography are necessary for the diagnosis of MacTel type 2, since 
they do not offer additional information to that provided by OCT-A.

\section{Conclusions}

MacTel type 2 is a complex pathology. OCT-A shows characteristic changes in the neurosensory retina and in the different capillary plexuses, without the need of other studies. Most patients have a visual acuity better than 20/40. The majority are in stage 2 and 3 according to the findings by OCT-A. We observed no correlation between our variables and the visual acuity of patients with this diagnosis. Diabetic patients with MacTel type 2 have a worse visual acuity. Pathological data is more evident in the neurosensory retina than vascular changes, supporting a cellular origin with secondary vascular disease. Likewise, OCT-A is the ideal study to detect early neovascularization in this disease. Biomarkers in OCT-A are difficult to determine for visual prognosis.

\section{Conflicts of interest}

The authors declare no conflicts of interest.

\section{Funding}

The authors declare that no funding was obtained for this publication.

\section{Ethical disclosures}

Protection of human and animal subjects. The authors declare that no experiments were performed on humans or animals for this study.

Confidentiality of data. The authors declare that they have followed the protocols of their work center on the publication of patient data.
Right to privacy and informed consent. The authors have obtained the written informed consent of the patients or subjects mentioned in the article. The corresponding author is in possession of this document.

\section{References}

1. Klein R, Blodi B, Meuer S Myers CE, Chew EY, Klein BE. The prevalence of macular telangiectasia type 2 in the Beaver Dam Eye study. Am J Ophtalmol. 2010;150:55-62.

2. Sallo F, Leung I, Mathenge W, Kyari F, Kuper H, Gilbert CE, et al. The prevalence of type 2 idiopathic macular telangiectasias in two African populations. Opthalmic Epidemiol. 2012;19:185-9.

3. Green W, Quigley H, De la Cruz Z, Cohen B. Parafoveal retinal telangiectasias. Light and electron microscopy studies. Trans Ophthalmol Soc UK. 1980;100:162-70.

4. Gass JD. Müller cell cone, an overlooked part of the anatomy of the fovea centralis: Hypotheses concerning its role in the pathogenesis of macular hole and retinoschisis. Arch Opthalmol 1999;117:660-73.

5. Mansour A, Schachat A. Foveal avascular zone in idiopathic parafoveal telangiectasia. Ophthalmologica. 1993;207:9-12

6. Gupta V, Gupta A, Dogra M, Agarwal A. Optic coherence tomography findings in group $2^{\mathrm{a}}$ idiopathic yuxtafoveolar telangiectasias. Ophthalmic Surg Laser Imaging. 2005;36:482-6

7. De Carlo T, Romano A, Waheed N, Duker J. A review of optical coherence tomography angiography (OCTA). Int J Retin Vitr. 2015;1(1):5.

8. Gass J, Blodi B. Idiopathic juxtafoveal telangiectasis. Update of classification and follow-up study. Ophthalmology. 1993;100:1536-46.

9. Thorell W, Zhang Q, Huang Y, An L, Durbin MK, Laron M, et al. Swept-Source OCT Angiography of Macular Telangiectasia Type 2, Ophthalmic Surgery, Lasers, and Imaging Retina. 2014;45(5):369-80.

10. Clemons T, Gillies M, Chew E, Bird AC, Peto T, Figueroa MJ, et al. Baseline characteristics of participants in the natural history study of macular telangiectasia MacTel Project Report No.2. Ophthalmic Epidemiol. 2010;17:66-73.

11. Spaide R, Klancnik J, Cooney M. Retinal Vascular Layer in Macular Telangiectasias Type 2 Imaged by Optical Coherence Tomographic Angiography. JAMA Ophthalmol. 2015;133(1):66-73.

12. Gass JDM. Histological study presumed parafoveal telangiectasia. Retina 2000;20:266-7.

13. Kuroda M, Hirami Y, Hata M, Mandai M, Takahashi M, Kurimoto Y. Intraretinal hyperreflective foci on spectral-domain optical coherence tomographic images of patients with retinitis pigmentosa. Clin Ophthalmol. 2014;8:435-40.

14. Heeren TF, Clemons T, Scholl HP, Bird AC, Holz FG, Charbel Issa P. Progression of visión loss in macular telangiectasias type 2. Invest Ophthalmol Vis Sci. 2015;56:3905-12.

15. Finger R, Charbel Issa P, Fimmers R, Holz FG, Rubin GS, Scholl HP. Reading performance is reduced by parafoveal escotomas in macular telangiectasia type 2. Invest Ophthalmol Vis Sci. 2009;50:1366-70.

16. Runkle AP, Kaiser PK, Srivastava SK, Schachat AP, Reese JL, Ehlers JP. OCT Angiography and Ellipsoid Zone Mapping of Macular Telangiectasia Type 2 From AVATAR Study. Invest Ophthalmol Vis Sci. 2017;58:3683-9.

17. Charbel Issa P, Gillies MC, Chew EY, Bird AC, Heeren TF, Peto T, et al. Macular telangiectasias type 2. Prog Retin Eyes Res 2013; 34:49-77. 